\title{
LA INTELECCIÓN SEGÚN LEONARDO POLO
}

\author{
INTELLECTION BY LEONARDO POLO
}

\author{
Juan A. García ${ }^{1}$ \\ Universidad de Málaga (España)
}

Recibido: 21-01-2014

Aceptado: 17-04-2014

Resumen: Se estudia en este trabajo la intelección en Polo, en los tres niveles que él distingue: el ser intelectual, la esencia intelectual y la operación intelectual. En los tres se descubre la dualidad de método y tema que impide la plena unidad de la perfecta intelección de sí.

Palabras-clave: Intelección, Polo, Luz, Límite mental.

\begin{abstract}
This work studies Intellection in Polo, in which he distinguishes three levels: the intellectual being, intellectual essence and intellectual operation. In all three the duality of subject and method, that prevents the full unity of perfect self-intellection, is discovered.
\end{abstract}

Key-words: Intellection, Polo, Light, Mental Limit.

Se suele decir que "inteligir" deriva del latín intus-legere: leer dentro. Y se quiere decir con ello que el objeto de la inteligencia es la esencia de los seres; es decir, aquello que interiormente les hace ser lo que son, tras su exterior aparecer ante los sentidos.

Con todo, también hay que distinguir, en primer lugar, entre el objeto adecuado a una inteligencia y el propio de la humana ${ }^{2}$, que es una inteligencia incorporada: el primero abarca todo cuanto es, mientras que el segundo se ciñe a los seres materiales, aquéllos de los que el hombre capta información mediante la sensibilidad. Por consiguiente, habrá que señalar la diferencia

[1] (jagarciago@uma.es) Catedrático de Teoría del Conocimiento de la Facultad de Filosofía y Letras (Universidad de Málaga).

[2] Plantearon esta diferencia los jesuítas conimbricenses de finales del s. XVI, y Polo la utiliza para defender el carácter simbólico de las ideas, del que luego hablaremos: cfr. Antropología trascendental, v. II. Eunsa, Pamplona 2003; p. 217, nt. 259. 
entre la información inicial de esos entes, que la inteligencia humana toma de la sensibilidad, y el conocimiento de su esencia, al que la inteligencia llega después, a partir de esa noticia inicial. Y luego, quizá cabría plantear también cuál sería el objeto de la inteligencia humana, si es que lo tiene, al margen del cuerpo: por ejemplo si le sobrevive. Por último, habrá que decir, en un segundo lugar, si hay algún modo, sea por analogía, por reflexión sobre la propia actividad intelectual o de otra manera, de que la inteligencia humana se eleve desde los seres materiales hacia los espirituales.

Y además, si la esencia se distingue realmente de la existencia, habrá también que decir cómo, siendo la esencia el objeto de la inteligencia, se puede entender, después de ella, la existencia.

\section{Planteamiento: la intelección en el plano del ser y en el de la acción}

En todo caso, discutiendo el objeto de la inteligencia para justificar su denominación, nos mantenemos en una consideración de la intelección en el plano de la operación: como el ejercicio de una actividad cognoscitiva, con la que se obtiene como resultado algo entendido. Mientras que la profundización que el enfoque de Polo nos propone al respecto consiste en considerar la intelección en el plano del ser, no sólo en el de la acción.

Esta profundización parece una continuación de la crítica aristotélica a Platón. Si el estagirita objetó a su maestro que el lugar de las ideas es el intelec$t o^{3}$, porque las ideas no se dan en sí, en un mundo ideal; Polo parece añadir a Aristóteles que el lugar del intelecto es la persona, porque las inteligencias no se dan en sí, ni en un orbe astral. No basta considerar la intelección como algo en sí, una actividad de un ente que existe al margen de ella; sino que hay que examinarla en el mismo orden del existente personal que la ejerce.

La fuerza de la posición aristotélica frente a Platón reside en que las ideas no son reales, sino intencionales. Lo propiamente real en la intelección es su ejercicio, más que su objeto; el cual es ideal y, según Aristóteles, inmanente a la operación misma; por eso, la actividad intelectual es previa a la idea que con ella se obtiene. Pero, entonces, lo primeramente real será el existente que entiende, el cual es previo y anterior a la operación que ejerce para entender.

$\mathrm{Y}$, en el orden del ser, la intelección es su manifestación: la expresión del ser; que, por manifestarse así, es un ser intelectual. Se podría considerar también que el fenómeno es cierta expresión de los seres materiales, su aparecer ante la sensibilidad. Pero, en todo caso, parece una expresión más bien pasiva y como necesaria; mientras que para que haya auténtica manifestación se requiere la actividad libre. Y como un ser intelectual y libre es un ser personal, la intelección es una manifestación de la persona.

[3] De anima III, 4; 429 a 25.

THÉMATA. Revista de Filosofía, Nº50 julio-diciembre (2014) pp.: 247-270 doi: 10.12795/themata.2014.i50.12 
Por eso, la intelección, más que hacia su término, hacia la idea, hacia lo entendido, hay que enfocarla hacia su origen. E interiorizarla del todo: no sólo para descubrirla como cierta operación que ejerce un ente a fin de obtener ideas, sino hasta percibirla como la manifestación operativa de un ser intelectual, como la expresión de su ser personal.

En este sentido, el planteamiento poliano acerca de la intelección es una profundización en el realismo aristotélico, como decimos; pero que, sin embargo, acepta a su manera el subjetivismo moderno. Por lo menos, el de aquélla actitud que adopta Kant cuando entiende que es "trascendental" la consideración del conocimiento como una acción humana, prescindiendo de lo conocido $^{4}$. O aquél otro de Hegel que se plasma en su Fenomenología del espíri$t u$; denominación que, como ha recalcado claramente Heidegger ${ }^{5}$, debe entenderse con genitivo subjetivo: pues los fenómenos lo son, sobre todo, del propio espíritu; el cual, precisamente así, mediante ellos, consigue realizar su índole reflexiva, que consiste en conocerse.

Conforme con lo que estamos diciendo, la teoría del conocimiento de Polo se encuentra en dos obras suyas distintas, que estudian respectivamente la operación cognoscitiva y el ser intelectual:

- el Curso de teoría del conocimiento ${ }^{6}$ trata de las operaciones cognoscitivas, de sus objetos y de los hábitos adquiridos por la inteligencia al ejercerlas, que precisamente permiten su progresivo despliegue ascendente.

Son tres las operaciones intelectuales que Polo distingue: la incoativa y las dos prosecutivas, que son negación y razón; ésta última con las tres fases usualmente admitidas: concepto, juicio y raciocinio (a las que Polo denomina verbalmente: concepción, afirmación y fundamentación).

A cada una de las operaciones, y de estas fases, sigue su hábito correspondiente; puesto que éstos, los hábitos adquiridos, son el conocimiento de la operación ejercida.

Los objetos de esas operaciones son, respectivamente, la noticia inicial, abstracta, la idea general y sus casos, y luego concepto, juicio y razonamiento objetivos.

Por otro lado, la razón, además de esta triple objetivación, tiene un uso explicitante, explicativo, que permite el encuentro de la causalidad; la cual constituye la esencia extramental: el universo físico.

[4] "Llamo trascendental a todo conocimiento que se ocupe no tanto de los objetos, cuanto de nuestro modo de conocerlos". Crítica de la razón pura A11, B25.

[5] Cfr. La fenomenología del espíritu de Hegel, Intr. § 30.

[6] 4 vv. Eunsa, Pamplona 1984-96.

THÉMATA. Revista de Filosofía, №50 julio-diciembre (2014) pp.: 247-270 doi: 10.12795/themata.2014.i50.12 
- Y luego está la Antropología trascendental ${ }^{7}$, que estudia otros actos intelectuales superiores: los propios del intelecto personal; y de los que dependen las operaciones de la inteligencia, con sus objetos y hábitos. Estos otros actos intelectuales son hábitos de la persona, de su intelecto, y superiores a los adquiridos por la inteligencia: porque no derivan del ejercicio de operaciones, sino que brotan del propio ser personal, al que manifiestan.

Los hábitos personales que registra Polo son tres: la sindéresis (es decir, la dualidad del yo cognoscente y el volente; o, con sus palabras, de "ver-yo" y "querer-yo"), el hábito de los primeros principios (que son tres mutuamente vigentes: la no-contradicción, la identidad y la causalidad trascendental) y la sabiduría, con la que el hombre sabe de sí: conoce su intelecto personal y se orienta hacia su destino (que es el verbo personal divino: pues la persona humana es la asimilación adverbial al Hijo ${ }^{8}$, o el adverbio -además-en busca del Verbo ${ }^{9}$ ).

Para asentar la intelección en el ser, Polo atribuye a la persona humana unos trascendentales que llama antropológicos, y que propone añadir a los trascendentales metafísicos tomados de la tradición: el ente, la unidad, la verdad y la bondad. Los trascendentales personales que agrega Polo son: el coexistir, la libertad, el entender y el dar, es decir, el amar donal. En esta ampliación me parece que se llaman trascendentales, sobre poco más o menos, a las que la propia tradición denominaba perfecciones puras del ser, entre las que se contaban, por ejemplo, el entender y el amar; las cuales sólo se muestran en los seres espirituales, dotados de más virtualidades que las que permite la materialidad. Estas perfecciones o trascendentales equivalen y se convierten entre sí, y con el ser personal. Concretamente, al entender trascendental, o sea, al ser intelectual de la persona, Polo lo denomina intelecto: el intelecto personal; en él estriba la radicación en el ser de la intelección.

Así que la teoría del conocimiento humano de Polo aboca finalmente al estudio del ser personal, de su intelecto; $y$, por tanto, de él nos ocuparemos en primer lugar. Aunque también habremos de tratar después de la inteligencia y su dinámica, que es la manifestación operativa del intelecto personal, es decir, la esencia cognoscitiva del ser intelectual. Finalmente, trataremos además del límite mental y su abandono, como una notable peculiaridad de la doctrina poliana sobre la intelección; se trata, a fin de cuentas, de que la inteligencia humana está incorporada, y el propio cuerpo es un hecho que late de algún modo bajo su operatividad, denunciando cierta limitación en ésta.

Se terminará por apreciar que en el tratamiento de esta triple temática subyace un planteamiento común: el que la intelección humana no es unitaria, sino dual. Por lo que en todos los niveles de la intelección humana se

[7] 2 vv. Eunsa, Pamplona 1999-2003.

[8] Polo, L.: Antropología trascendental, v. I; p. 214.

[9] Polo, L.: Antropología trascendental, v. I; p. 226, nt. 40.

THÉMATA. Revista de Filosofía, №50 julio-diciembre (2014) pp.: 247-270 doi: 10.12795/themata.2014.i50.12 
distinguen dos: el método y el tema; es decir, el ejercicio de la intelección y lo entendido con ella. Se rechaza así completamente la reflexión cognoscitiva.

\section{El intelecto y la persona}

Considerado el conocimiento como manifestación del ser, lo notable es que, si la intelección fuera una manifestación plena y perfecta de la persona, sería otra persona idéntica con la primera, que conseguiría así replicarse. En cambio, el hombre no consigue al conocerse una manifestación de sí mismo tan perfecta; pues, como lo suele decir Polo: el yo pensado no piensa ${ }^{10}$, ya que a la idea de sujeto le falta precisamente lo que distingue al sujeto de la idea; a saber: ver ${ }^{11}$.

Polo entiende la identidad del ser, que sólo puede ser originaria porque es imposible obtenerla con ningún proceso generador de ella, como la identidad de un ser consigo mismo al expresarse. Esta identidad asume la de la existencia con su esencia, y la del ser con el obrar; y consiste propiamente en la replicación interior: en la dualidad de personas interna a un único ser, justamente porque en su intimidad se expresa completa y acabadamente.

Así es como Polo comprende la interpretación que Tomás de Aquino hace de la noesis noeseos aristotélica para explicar la generación del verbo personal divino, es decir, de la segunda persona de la trinidad ${ }^{12}$. Como en Dios el ser y el obrar no se distinguen, su entender, el verbo divino, es su propio ser ${ }^{13}$; y así el hijo y el padre son idénticos: un solo Dios. En el que sólo se distinguen relaciones, como la de generar el verbo y ser éste generado, que subsisten y permanecen en el interior del único ser divino: son sus personas, al menos la del padre y el hijo.

Para Aristóteles, en cambio, noesis noeseos es la unidad de quien entiende y lo entendido ${ }^{14}$, es decir, de la actividad noética y su objeto, que en Dios no se distinguen. Pero, para el aquinate, tanto como unidad, en Dios hay dualidad: la de padre e hijo; porque quien entiende se replica en su entenderse, siendo ambos idénticos. La unidad realmente más profunda no es la que aúna operación y objeto, sino la que identifica el ser y el obrar. Por el contrario, ninguna criatura se replica a sí misma; todo lo más, las criaturas se reproducen: se duplican hacia fuera, perdiendo la propia identidad; sólo Dios es un ser idéntico consigo mismo, que se replica en su interior.

[10] Antropología trascendental, v. II; p. 44.

[11] Polo, L.: Evidencia y realidad en Descartes. Rialp, Madrid 1963; p. 306.

[12] Cfr. Summa theologiae I, 14, 2; más ampliamente I, 30, 2; y, en general, I, 27-43.

[13] Verbum divinum est eiusdem naturae cum Deo, et subsistens in natura divina: Tomás de Aquino: De differentia verbi divini et humani, $\mathrm{n}^{\circ} 293$.

[14] Cfr. Metafísica XII, 9.

THÉMATA. Revista de Filosofía, №50 julio-diciembre (2014) pp.: 247-270 doi: 10.12795/themata.2014.i50.12 
La expresión de un ser es, al tiempo, su manifestación y su fecundidad. Pero el hombre se manifiesta en su interior, porque la sabiduría es un hábito inmanente del intelecto personal; en cambio, es fecundo hacia el exterior mediante su esencia espiritual, que incluye un organismo natural. Por eso comprende con más facilidad la generación de un verbo personal en Dios que la expiración del espíritu divino.

En cualquier caso, en el hombre se distinguen, no ya padres e hijos, sino también la persona y su propia expresión; es decir, el ser personal y su obrar, o el acto de ser persona y la esencia operativa de que dispone. La persona humana, por tanto, carece de réplica; ya que el hombre no se expresa a sí mismo de un modo pleno y completo. Por esto, el hombre no puede identificarse enteramente con ninguna de sus realizaciones.

\section{a) La transparencia del intelecto: alcanzarse y buscarse}

Si el ser personal humano, como carente de réplica, no consigue encontrarse en ninguna de sus obras, entonces ninguna intelección humana es el intelecto que la ejerce. El hombre no puede conocerse a sí mismo perfectamente: con identidad entre quien conoce y su conocerse. Por ello, Polo rechaza tajantemente la reditio in se ipsum reditione completa que el neoplatonismo atribuyó a los seres con una esencia inmaterial ${ }^{15}$. En cambio, si a la esencia se añade el ser, y se plantea la eventual identificación o distinción entre ambos, se logra el planteamiento tomista que Polo adopta: la réplica de un ser en su conocerse, que sólo alcanza Dios. Por el contrario, la intelección humana, y por creada, es decir, por carente de identidad, se caracteriza siempre por la dualidad entre el acto cognoscitivo y lo conocido con él. Por ello el intelecto humano siempre se distingue del saber sobre sí que alcanza.

Eso no significa que el intelecto personal no se conozca a sí mismo de ninguna manera. Porque, en la propia carencia de réplica, hay una precisa indicación sobre el ser personal: la de que, si en ninguna de sus obras se encuentra, eso acontece porque él mismo es "además" de ellas. Opino que Polo acuña la expresión "ser además" para designar al ser personal humano, justamente en atención a la carencia de réplica que le caracteriza como criatura. El ser personal es además de cualquier obra suya; y por tanto el intelecto personal se distingue de cualquier intelección, o incluso intelección de sí, que logre. Pero, con todo, pese a que no puede identificarse a sí mismo con ninguna idea sobre sí que forje, el hombre sí que puede, hasta cierto punto, conocerse, y sin reflexión: precisamente cuando descubre su ser "además". Y, en esta medida, puede decirse que el intelecto personal alcanza a saber de sí; incluso que la sabiduría humana consiste precisamente en eso: en que el intelecto se conozca a sí mismo como "además".

[15] Omnis sciens qui scit essentiam suam est rediens ad essentiam suam reditione completa. Liber de causis XV, 124.

THÉMATA. Revista de Filosofía, №50 julio-diciembre (2014) pp.: 247-270 doi: 10.12795/themata.2014.i50.12 
Sin olvidar nunca que la carencia de réplica impide una estricta autognosis; o que al descubrir su ser "además", el intelecto personal tan sólo se alcanza, es decir, tan sólo consigue saber algo de sí mismo: el que existe; lo que es insuficiente, porque aún le falta saber qué es, quién es el que existe. La persona como tal, y su intelecto en particular, no se encuentran en ninguna de sus obras y manifestaciones, ni tampoco en ese saber de sí que alcanzan.

Alcanzarse como además de cualquier expresión propia permite entonces al intelecto mantenerse como término de búsqueda: el intelecto personal no sólo se alcanza, sino que también se busca. Ambas cosas, alcanzarse como "además" y además, reiterativamente, buscarse, suceden justamente porque el ser personal no se encuentra en ninguna de sus obras o manifestaciones.

En esta reiteración, alcanzarse y buscarse, se aprecia que el carácter de "además" es, como dice Polo, dual: metódico y temático ${ }^{16}$. La precariedad del método, del solo alcanzarse, que sin reiteración temática se supondría ya conocido y decaería en el límite, requiere la solidaridad con su tema, que es también "además": la búsqueda persigue entonces el además del "además".

De modo que, como el ser personal no se encuentra a sí mismo en sus obras, el intelecto personal se sabe "además", de acuerdo con su dimensión metódica; pero, como no se encuentra a sí mismo en ellas, además, otra vez "además" insisto, no se identifica con ninguna de ellas, ni siquiera con este saberse "además": y así descubre su dimensión temática. Entonces se sigue buscando; se busca, es decir, busca su identidad, su réplica.

Aunque carece de ella, la busca, porque sin ella no podría identificarse a sí mismo: se desconocería a sí mismo definitivamente. Y resultaría muy extraño que un intelecto: que se define por la intelección, que con ella se expresa y manifiesta, y que con ella consigue conocer la esencia de otros, e incluso de todos los demás seres, él mismo hubiera de permanecer ignoto: ciego e indescifrado para sí mismo; no tendría sentido.

Alcanzarse y buscarse, entonces, se distinguen, aunque no se oponen; porque lo uno conduce a lo otro. Pues no por alcanzarse el intelecto personal se conoce acabadamente: sabe que existe, que es "además", pero no sabe qué es, quién es: no conoce enteramente su ser. No se reconoce en su saber de sí: no se identifica a sí mismo, porque carece de identidad. Y entonces, el intelecto personal pasa a buscarse, a buscar su identidad, su réplica.

$\mathrm{Y}$, como de alcanzarse pasa a buscarse sin ninguna dificultad, sin resistencia alguna, será porque es transparente; de manera que, cuando se alcanza, como sigue buscándose, ejerce y aprecia su propia transparencia. La transparencia del intelecto personal es la solidaridad entre la dimensión metódica y la temática que le corresponden como acto cognoscitivo que es.

[16] Cfr. Antropología trascendental, v. I; pp. 196-7.

THÉMATA. Revista de Filosofía, №50 julio-diciembre (2014) pp.: 247-270 doi: 10.12795/themata.2014.i50.12 
Transparente es, ante todo, aquello que la luz traspasa; lo traslúcido, que se deja atravesar por la luz sin opacidad ninguna. Y tal es el intelecto personal en su interior: cuando arroja luz en su propia luz, es decir, cuando se alcanza como "además" y luego continúa buscándose, buscando su identidad; en este tránsito hacia la réplica consiste su propia transparencia.

Transparente es, también, lo que deja ver a su través. Y así, el verbo divino, como manifestación del ser idéntico que se replica en él, lo deja ver a su través: la transparencia de la originaria réplica del ser idéntico es absoluta y perfecta. La criatura material, el universo, aunque al causar demuestre persistentemente la existencia de la identidad originaria del ser, no la deja ver: porque no permite a la mente ingresar en su interior; ya que, precisamente, la existencia del universo es extramental; de modo que esa criatura sólo es un cierto vestigio de su creador. En cambio, la criatura personal es imagen de Dios; su transparencia creada, cuando a su través no permite ver enteramente al creador (pues el verbo divino es, en el mejor de los casos, un don futuro; y una réplica inabarcable por el hombre), al menos siempre permite orientarse hacia él y buscarle. En este sentido, también es transparente el intelecto personal: porque deja vislumbrar la réplica sin declararla.

\section{b) La luz iluminante: encontrar y ver}

De la transparencia se distingue la iluminación; que es la luz intelectual cuando no se vuelca sobre sí misma, sino que se vierte hacia fuera: hacia realidades distintas de ella; y en las que, al iluminarlas, termina o acaba, coincide con ellas, porque no las traspasa.

Aristóteles decía que la inteligencia humana parece ser siempre de otra $\cos a^{17}$, frente a la inteligencia divina, que es noesis noeseos. Y ahora señalamos, en su favor, que el intelecto personal ilumina, para conocerlas, otras realidades distintas de sí mismo. Pero recordamos, en su contra, que también exhibe su propia transparencia cuando se alcanza como "además", porque entonces inmediatamente se traspasa para buscarse. Esto no lo sabía Aristóteles, que ni se figuró la existencia de una réplica del ser en su entender, distinta pero idéntica con él; es decir, de una perfecta expresión de aquél en éste.

Por su parte, Polo asocia la dualidad transparencia e iluminación con la distinción real tomista de existencia y esencia. Para afirmar que, como el hombre carece de réplica, en él se distinguen su existencia y su esencia, el coexistir personal y su manifestación operativa. Lo que, en el caso de la intelección, distingue la luz intelectual -transparente- de la iluminación en que se muestra. Alcanzarse el intelecto en su ser "además" y buscar la réplica es la transparencia del intelecto: la luz intelectual por dentro. En cambio, la luz iluminante, la que se vierte al exterior, es la manifestación esencial del intelecto personal, es decir, del ser intelectual.

[17] Metafísica XII, 9; 1074 b 35.

THÉMATA. Revista de Filosofía, Nº50 julio-diciembre (2014) pp.: 247-270 doi: 10.12795/themata.2014.i50.12 
De acuerdo con esta asociación, la esencia, aunque considerada en sí misma sea actividad, en comparación con el acto de ser, vista desde él, es potencia. Porque el ser personal humano carece de identidad, no puede replicarse; lo que sí puede, en cambio, es expresarse y manifestarse hasta cierto punto. La esencia es entonces el potencial del acto de ser; y el potencial del intelecto personal, su manifestación, es la iluminación. El intelecto personal no puede replicarse: no se encuentra en sus obras, y por eso se busca; se alcanza como "además", según su dimensión metódica, y se sigue buscando aun privado de ella, de acuerdo con su sentido temático. Pero, en cambio, el intelecto personal sí que puede manifestarse, e iluminar otras realidades distintas de sí mismo.

Si no puede replicarse, sí que puede iluminar; y, al iluminar, encontrar y ver. Son otros dos actos del intelecto personal: alcanzarse, buscarse... y ahora encontrar y ver (un ver intelectual, claro está: el entender, no la visión sensible). Se alcanza y se busca hacia dentro, en la intimidad de la persona; en cambio, se encuentra y se ve mirando hacia fuera, al exterior.

Propiamente, la manifestación del intelecto personal, la iluminación, lo que pide es ver aquello que se ilumina: puesto que se ilumina, a fin de cuentas, para verlo; aunque haya también otros encuentros que no permiten la visión. Esta exigencia de visión se justifica en que la esencia de la persona humana, lo que el ser humano es, es un yo, es decir, una esencia espiritual: dotada de dos potencias que son la inteligencia y la voluntad. Porque de la persona no procede otra persona; pero no por eso su existencia es infecunda, sino que de la persona procede el $\mathrm{yo}^{18}$, del acto de ser personal la esencia de la persona: el espíritu humano y su obrar. Como el espíritu humano dispone de dos potencias, el yo humano no es sólo cognoscente, vidente, sino también volente y actuante; una dualidad interna a la esencia de la persona.

$\mathrm{Al}$ ser la fecundidad de la persona de orden esencial, hacia fuera, se requiere completar la interior donación personal con el don efectivo, forjado en la práctica: es lo que pide el refrán "obras son amores". Y, por eso, para constituir el acto voluntario inicial, llamado por la tradición simplex velle, Polo propone una especial iluminación de la voluntad por parte de la persona. Por esta razón al iluminar global del intelecto personal lo asocia Polo con el que la misma tradición denominó hábito innato de la sindéresis ${ }^{19}$, al que se atribuían en particular los primeros principios prácticos.

Esto no obstante, lo propio del yo cognoscente es ver. Y decimos entonces que se distinguen encontrar y ver. La diferencia está en que se encuentra, sin llegar a ver, aquello que es independiente de la iluminación, porque es previo a ella y no se ve afectado por ella. Por contra, se ve lo que depende de la iluminación, porque es suscitado por la luz iluminante. $\mathrm{Al}$ modo como los colores los forma la

[18] Cfr. Polo, L.: Antropología trascendental, v. I; p. 210.

[19] Cfr. Antropología trascendental, v. II; p. 132.

THÉMATA. Revista de Filosofía, №50 julio-diciembre (2014) pp.: 247-270 doi: 10.12795/themata.2014.i50.12 
luz al iluminar lo visible, es decir, los conforma con ello, de modo que se dice que los colores son efectos formales de la luz; así también lo visto por la inteligencia es suscitado por la iluminación mental, es decir, es conformado por ella, junto con lo visible. En cambio, se encuentra lo que no se debe a la iluminación ni es afectado por ella, puesto que la precede y es inmune a ella.

Lo que el intelecto personal encuentra son los principios; que, precisamente como tales, anteceden a su iluminación, no se deben a ella y no pierden su carácter de principios por recibirla. Tanto los primeros principios, cuya universal evidencia indica que no dependen de las propias luces; como los principios predicamentales o causas, que están coordinados con la inteligencia humana, pero como distintos de ella. Los primeros principios, en su mutua vigencia, los advierte el intelecto personal prescindiendo de las operaciones de la inteligencia; en cambio, las causas las explicita mediante la operación racional de aquélla. Estos dos tipos de principios equivalen a la existencia y esencia extramentales; y son la temática de la metafísica y de la ontología, a la que Polo llama física de causas.

No obstante, estos encuentros del intelecto personal, cuando advierte o explicita, requieren la iluminación; y, como lo propio de ésta es ver, que es lo que caracteriza al yo cognoscente, guardan también alguna relación con la visión. Los primeros principios se encuentran prescindiendo de la visión, deponiéndola, porque están por encima del yo; pues la advertencia de la mutua vigencia de los primeros principios apunta a la identidad originaria del ser como insondable, y ante ella el yo desaparece en la adoración ${ }^{20}$. En cambio, las causas se encuentran en contraste con la visión, y como en pugna con ella ${ }^{21}$ : porque, al estar lo mental y lo físico coordinados, hay que discernir entre ambos para separarlos. La esencia extramental se contradistingue así de la esencia humana, esto es, del yo, y como algo inferior a él.

Hay un tercer encuentro temático al que conviene la denominación más precisa de ser un hallazgo: porque tanto es parcialmente visto como parcialmente encontrado; y es la intencionalidad de los objetos pensados. Y es que $n i$ la intencionalidad objetiva, ni la pugna de la presencia mental con la concausalidad, ni la advertencia del hábito de los primeros principios son encuentros que susciten ${ }^{22}$; mientras que, en cambio, el yo cognoscente precisa suscitar para ver, inventar para encontrar: la iluminación inventa -suscita- lo inteligido ${ }^{23}$. Por esta razón los objetos pensados, salvo las segundas intenciones lógicas, no forman parte de la esencia del hombre ${ }^{24}$, pues el hombre no puede disponer de

[20] Polo, L.: Antropología trascendental, v. I; p. 211.

[21] Sobre esta pugna, cfr. Polo, L.: Curso de teoría del conocimiento, v. IV-1ª parte; pp. 1-35.

[22] Polo, L.: Antropología trascendental, v. II; p. 62, nt. 60.

[23] Polo, L.: Antropología trascendental, v. II; p. 62.

[24] Polo, L.: Antropología trascendental, v. I; p. 162.

THÉMATA. Revista de Filosofía, Nº50 julio-diciembre (2014) pp.: 247-270 doi: 10.12795/themata.2014.i50.12 
ellos. Este tercer encuentro temático, de peculiar estatuto por ser propio del yo cognoscente, es con todo inferior a él, y no real sino intencional; por lo que sólo es avistado desde la exención de ser, propia de la presencia mental, que permite la visión. Por eso es un hallazgo del yo cognoscente, y no un encuentro del intelecto personal.

\section{La inteligencia y el yo}

Aparte de estos encuentros, insisto en que lo propio del intelecto personal al iluminar es ver. Sin embargo, para ver, no basta iluminar, un cierto acto del intelecto personal; sino que hace falta también la capacidad de ver. Que a su vez procede también de la persona: porque, para captar lo visible, que es formado al iluminar, el intelecto personal suscita una potencia en la esencia humana, la inteligencia. El yo cognoscente ha de aunar, entonces, iluminación y visión: su dependencia de la persona y la índole visiva, vidente, propia de su esencia.

Si hasta ahora, para hablar del intelecto personal, Polo se ha basado en una doctrina tomista: la identidad del ser consigo mismo frente a la distinción real de existencia y esencia; a fin de señalar la diferencia entre la transparencia propia de la luz intelectual y la iluminación de otras realidades; en este momento, para comprender la doctrina de Polo sobre la iluminación y la visión, que es la manifestación esencial del intelecto personal, hay que retroceder a la distinción aristotélica entre intelecto agente y paciente. Porque, frente al acto del intelecto personal que es iluminar, la inteligencia es la potencia intelectual: la capacidad de ver propia de la esencia humana, o propia de un yo. Y lo primero es señalar la insuficiencia de la doctrina aristotélica al respecto.

\section{a) La potencia intelectual y la actividad cognoscitiva del yo.}

Para Aristóteles, la unión de iluminación y visión es, en rigor, la operación intelectual: pues el estagirita es el descubridor de la "praxis teleia", es decir, de las operaciones intelectuales, que son para él las propiamente temáti$\operatorname{cas}^{25}$; Aristóteles es el pensador de la teoría. Pero la operación remite a la potencia intelectual; por eso, al fijarse en ella, el estagirita ignora, no ya la noción de persona, que no es griega, sino incluso la del yo cognoscente. Porque es patente que la interioridad del yo, del espíritu humano, va más allá de las operaciones intelectuales, que más bien nos ponen en contacto con lo exterior e inferior.

$\mathrm{Y}$ es que Aristóteles procede según una analogía que pivota sobre la potencia, pues parte del modelo del conocimiento sensible ${ }^{26}$ : a las facultades orgánicas les llega la información del exterior, y son capaces de adaptarse a

[25] Polo, L.: Antropología trascendental, v. II; p. 61.

[26] El libro III del De anima es la continuación del II.

THÉMATA. Revista de Filosofía, №50 julio-diciembre (2014) pp.: 247-270 doi: 10.12795/themata.2014.150.12 
ella para conocerla; padecen la impresión producida desde el exterior y son capaces de expresarla interiormente cuando la conocen. Análogamente, a la capacidad intelectual, es decir, al intelecto paciente, le debe de llegar una información inteligible que lo impresione y así lo active; de modo que ejerza la operación de entender, y exprese esa información con alguna idea o verbo mental: así acontece la visión intelectual.

Pero como la información que recibe el hombre es sensible, para hacerla inteligible se precisa la intervención del intelecto agente, que salva la diferencia entre lo material y lo espiritual. Aceptando entonces otra analogía platónica entre la visión sensible y la inteligible (el sol se comporta en la esfera de lo visible en relación con la visión y lo visto, como el bien en la esfera de lo inteligible en relación con la inteligencia y lo entendido por ella ${ }^{27}$ ), Aristóteles distingue la dimensión activa de la intelección, que es como la luz del sol interiorizada en el hombre para iluminar los fantasmas sensibles y hacerlos inteligibles, respecto de la dimensión pasiva de la intelección, que recibe lo inteligible y lo expresa al verlo.

La analogía aristotélica es ilustrativa, y se sostiene; pero al mismo tiempo es muy deficiente: porque las nociones de especie impresa inteligible y de intelecto paciente son metafóricas, o inaceptables; ya que la inteligencia es inmaterial. Esta deficiencia denuncia la analogía con la sensibilidad de la que procede el planteamiento aristotélico, la cual conlleva cierta prioridad de la potencia en la explicación de la intelección, que entonces queda reducida a la operación intelectual. Por eso, para Aristóteles, la unión de intelecto agente y paciente se reduce a la operación mental.

Frente a esto Polo sostiene la prioridad del acto, de la iluminación, sobre la capacidad de ver que suscita, pues sólo un acto puede suscitar una potencia, y no al revés ${ }^{28}$, y sobre las operaciones con que ésta se activa. Por eso el intelecto agente no se agota en la iluminación de los fantasmas sensibles, sino que sigue iluminando después: por ejemplo, la propia operación intelectual ejercida; y así la inteligencia adquiere hábitos, que la repotencian capacitándola para nuevas y superiores operaciones. Todo ello apunta ya a la interioridad del espíritu humano, al yo cognoscente. En cambio, Aristóteles sólo apela al intelecto agente para abstraer, es decir, para salvar la diferencia entre lo sensible y lo inteligible, y así hacer posible la operación intelectual.

El aristotelismo medieval ya se percató de que la intelección humana no consistía solamente en esa abstracción, la del intelecto agente; y añadió a ella las que llamó abstracciones del intelecto paciente: total o formal, ésta última con tres grados ${ }^{29}$. Por esta razón, si Aristóteles consideraba el intelecto agente

[27] República VI, 19; 508 c.

[28] Antropología trascendental, v. II; p. 69.

[29] Cfr. García López, J.: "La abstracción”. En: Estudios de metafísica tomista. Eunsa, Pamplona 1976; pp. 15-30.

THÉMATA. Revista de Filosofía, N50 julio-diciembre (2014) pp.: 247-270 doi: 10.12795/themata.2014.i50.12 
y paciente como dos dimensiones de la intelección, la tradición aristotélica de la edad media las separó para considerarlas como dos facultades distintas de la naturaleza humana. Incluso algunos pensadores árabes medievales sostuvieron que el intelecto agente era único para todos los seres humanos, y estaba ubicado en la última esfera astral ${ }^{30}$.

\section{b) La actividad cognoscitiva del yo y la persona}

Desde esta perspectiva, que apunta una evolución histórica en la noción de intelecto agente ${ }^{31}$, se ha opinado que Polo traslada el intelecto agente desde una potencia de la naturaleza humana hasta el acto de ser personal, para considerarlo como un trascendental de la persona, a saber: como el intelecto personal ${ }^{32}$.

Esto puedo decirse así, y el propio Polo así lo dice: porque iluminar es un acto, un hábito, del intelecto personal. Pero, en contra, también hay que señalar que no se identifica con él: porque se distinguen realmente el iluminar y la transparencia del intelecto; de modo que el intelecto agente no es el intelecto personal.

También, porque lo que el intelecto personal busca, su tema, es el verbo divino, la réplica; en cambio, ilumina a la inteligencia para ver. Llegar a decir que el objeto del intelecto agente es Dios asociaría, de un modo confuso, la búsqueda de réplica y la visión de Dios: lo que amenaza un ontologismo contra el que Polo ha advertido ${ }^{33}$; y que no distingue, aunque ambos sean idénticos, el origen y su réplica.

$\mathrm{El}$ intelecto agente es más bien la manifestación esencial del intelecto personal: su virtualidad para iluminar hacia fuera y permitir la visión de lo inferior. El motivo más definitivo para mantener esta opinión mejor que la anterior es que Aristóteles atribuye la inteligibilidad actual de los fantasmas al intelecto agente, mientras que Polo se la atribuye ya a un hábito del intelecto personal: precisamente en atención a que es una luz iluminante y no transparente (se trata del hábito de la sindéresis ${ }^{34}$, de la iluminación). Atribuirle la transparencia modificaría el sentido de la noción aristotélica de nous poieti$k o ́ s^{35}$, algo que es inconveniente porque el estagirita es el autor de esa noción.

En todo caso, lo que hay que notar es que Aristóteles distingue dos dimensiones al explicar la operación intelectual: el intelecto paciente y el agente; mientras que Polo, en cambio, distingue tres actos intelectuales de distinto rango:

[30] Cfr. Robles Ortega, A.: La teoría del conocimiento en la tradición aristotélica (siglos IV a C.XIII d. C.). Universidad, Granada 1997.

[31] Cfr. Sellés, J. F.: El intelecto agente y los filósofos. Eunsa, Pamplona 2012.

[32] Cfr. Sellés, J. F.: El conocer personal. Estudio del entendimiento agente según Polo. Universidad de Navarra, Pamplona 2003.

[33] Cfr. Antropología trascendental, v. II; p. 84.

[34] Cfr. Antropología trascendental, v. II; p. 22, nt. 38.

[35] Cfr. White, M. J.: The problem of Aristotle's "nous poietikós". "The review of metaphysics" Washington [USA] 57 (2004) 725-39.

THÉMATA. Revista de Filosofía, №50 julio-diciembre (2014) pp.: 247-270

doi: 10.12795/themata.2014.i50.12 
ver, iluminar y la transparencia del intelecto personal. Los dos primeros, ver e iluminar, se corresponden suficientemente bien (ahora precisaremos las diferencias) con el intelecto paciente y agente; $y$, en la medida en que iluminar remite al intelecto personal, pues es un hábito suyo, se puede decir que Polo retrae el intelecto agente hacia la persona. Pero, insisto: sólo hasta llegar, en el mejor de los casos, al yo cognoscente; no hasta identificar intelecto agente y persona, porque además de la iluminación está la transparencia del intelecto personal. El yo cognoscente es quien aúna iluminación y visión, incluso por encima de la operación; que es como las aunó Aristóteles, más bien desconocedor de las interioridades del yo.

\section{c) Iluminación y visión}

Lo más notable en la doctrina de Polo sobre la inteligencia es, en mi opinión, la interacción de intelecto agente y paciente que plantea, el juego entre iluminar y ver que permite elevarse hasta el yo cognoscente. Y es que Polo distingue como una doble cascada en su interior.

La ascendente es la iluminación, propia del intelecto agente: que se eleva desde los fantasmas sensibles hasta los hábitos adquiridos, y va suscitando así lo visible. La descendente es la visión, propia de la inteligencia: que va desde la experiencia intelectual que aclara los hábitos adquiridos, hasta la intencionalidad de los objetos abstractos cuando se convierten a la fantasía.

Esta doble cascada exige la interacción entre intelecto agente y paciente, o el juego entre iluminación y visión; los cuales comportan dos extremos:

1) Ante todo, un doble refuerzo mutuo entre ambos, que expande la interioridad del yo cognoscente más allá de la operación intelectual:

- En concreto, la extensión de la actividad del intelecto agente, su ampliación: pues ya no sólo ilumina los fantasmas sensibles, sino luego las interioridades del propio espíritu: los objetos inteligibles, las operaciones intelectuales ejercidas y los hábitos adquiridos ${ }^{36}$.

De tal modo que la iluminación de los fantasmas activa la potencia y suscita su operación inicial; pero la posterior iluminación de la operación ejercida suscita los hábitos intelectuales, que intensifican la capacidad intelectual para ejercer nuevas operaciones superiores a la inicial, las prosecutivas; las cuales requieren a su vez la iluminación de los objetos inteligibles que las preceden, cuyo mejor entendimiento es esa prosecución.

Finalmente, la ulterior iluminación de los hábitos adquiridos permite a la potencia adquirir experiencia; y la experiencia intelectual es el nivel más alto de la intelección esencial del hombre.

[36] Los hábitos intelectuales, las operaciones y los objetos son los niveles de "ver-inteligido": Polo, L.: Antropología trascendental, v. II; p. 71, nt. 89.

THÉMATA. Revista de Filosofía, N50 julio-diciembre (2014) pp.: 247-270 doi: 10.12795/themata.2014.i50.12 
- Y, por otro lado, la repotenciación de la capacidad intelectual que esa extensión de la actividad del intelecto agente conlleva: el crecimiento de la inteligencia como potencia; el cual, como la inteligencia es infinita por inmaterial, es un crecimiento irrestricto.

Así, se puede conceder que la inteligencia halla, y ve, la intencionalidad del objeto abstracto, cuando lo remite a sus antecedentes sensibles convirtiéndolo a la fantasía; pero, halla y ve también la intencionalidad de los objetos inteligibles superiores vertiéndolos hacia los inferiores (son también las segundas intenciones, y sus segundas determinaciones).

Y, además, ve las operaciones desde los hábitos adquiridos cuando las idea y simboliza; e intensifica su visión, ve esas ideas simbólicas aún con mayor claridad, desde la experiencia intelectual.

Todo esto es el crecimiento de la inteligencia, el incremento de su visión, de lo que la inteligencia ve, cuando el intelecto personal amplía su actividad iluminadora para permitirlo.

En suma, la iluminación y la visión se extienden, se amplían, hasta englobar toda la dinámica de la inteligencia, todo lo intelectual de la esencia humana; y así el yo cognoscente gana en profundidad, en interioridad, por encima de la sola operación intelectual.

2) Por tanto, la mutua interacción de intelecto agente y paciente comporta también la multiplicación de las luces mentales del hombre, pues iluminar no es una acción única: no ya para toda la especie humana, como sostuvieron algunos averroístas; sino, ni siquiera, para cada persona.

Y es que la luz del intelecto personal se analiza en el orden de la esencia humana en una pluralidad de luces mentales, luces intraesenciales como dice Polo; porque el hombre puede ver muchos asuntos distintos y con distintas luces. Pero, sobre todo, porque puede ver sus propios actos de visión: lo que Polo denomina ver-inteligido. Y, en su ápice, la iluminación del intelecto personal engloba todo cuanto uno ve, ya que todas las luces mentales dependen de ese iluminar propio de la persona: así se descubre el yo cognoscente.

\section{d) La visión intelectual y el yo cognoscente}

A este respecto, Aristóteles afirmaba que el alma es en cierto modo todas las $\operatorname{cosas}^{37}$; y entendía con ello que la inteligencia es como una tabla rasa en la que se puede imprimir cualquier forma abstraída de la sensibilidad: la potencia intelectual es así capaz de recibir todo lo inteligible. Pero Polo sugiere

[37] De anima III, 8; 431 b.

THÉMATA. Revista de Filosofía, №50 julio-diciembre (2014) pp.: 247-270 doi: 10.12795/themata.2014.i50.12 
ampliar esta sentencia aristotélica atendiendo a la pluralidad de actos cognoscitivos del alma que no iluminan cosas físicas ${ }^{38}$; para afirmar que la potencia intelectual no sólo conoce los inteligibles tomados de la sensibilidad, sino que puede conocer también lo que no es sensible sino intelectual; porque el intelecto agente no sólo ilumina los fantasmas sensibles para hacerlos inteligibles, sino luego los propios actos intelectuales, y sus objetos y hábitos.

Así, la entera dinámica de la inteligencia se eleva desde el orden sensible, material, al orden intelectual e inteligible: las propias luces mentales con las que el hombre ve, los actos cognoscitivos, pueden ser iluminadas y vistas, es el ver-inteligido. De modo que el intelecto personal no sólo ilumina lo oscuro para hacerlo visible, sino que ilumina las propias luces mentales. Por así decirlo, no sólo se ven los colores, sino también luces luminosas: que iluminan y a su vez lucen, es decir, son vistas.

El ver-inteligido son iluminaciones iluminadas, y así vistas; o, en su ápice, englobadas por la iluminación que procede del intelecto personal. Y justamente ese ápice, por encima incluso de la visión, es el yo cognoscente; el cual prescinde ya de la potencia intelectual porque depende directamente de la persona, de la iluminación procedente del intelecto personal... cuando no se busca a sí mismo, u olvidado de sí.

El yo nunca es visto, sino que siempre es el que ve. No es visto, sino que su plural ver depende de la iluminación del intelecto personal... si es ampliada para englobar todo lo intelectual; ampliación con la que manifiesta su proceder de la persona, cuando ésta omite la búsqueda de sí.

$\mathrm{Si}$ el yo cognoscente es un ver nunca visto, eso sucede porque es un acto cognoscitivo cuya dimensión metódica no es solidaria con su dimensión temática; pues el iluminar remite al ser personal, mientras que lo iluminado y visto se incluye en la esencia de la persona. Más que de solidaridad metódico-temática, aquí cabe hablar de afinidad, porque en lo iluminado no está ausente lo intelectual $^{39}$; y en esto se distingue la iluminación englobante de los otros hábitos de la persona: del de sabiduría, que goza de la solidaridad metódico-temática, y del de los primeros principios, que ni siquiera encuentra afinidad entre tema y método.

El yo cognoscente, en último término, es el iluminar, en cuanto englobante de todo cuanto cada quien ve. El yo como englobante ni es el reconocimiento de la conciencia, ni ninguna generalización de ella, objetos de particulares operaciones mentales; por lo mismo que se distingue también de la noción kantiana de conciencia trascendental, o de la hegeliana de posibilidad infinita que se realiza concretando lo universal. Sobre todo, prescindiendo de afinidades y detalles, porque el yo no es visto, sino un ver. Llega a ver sus propios actos de visión; pero, cuando éstos son vistos, él es quien los ve. Por eso

[38] Antropología trascendental, v. II; p. 74.

[39] Cfr. Polo, L.: Antropología trascendental, v. I; p. 199.

THÉMATA. Revista de Filosofía, Nº50 julio-diciembre (2014) pp.: 247-270 doi: 10.12795/themata.2014.i50.12 
no hay noción de él, ni una ni otra ni ninguna; sino que es el iluminar englobante. Y, aunque es un iluminar procedente del intelecto personal, tampoco es un encuentro suyo, difícil o imposible de ser visto; porque, si no es un fruto de ella, tampoco antecede a la iluminación: sino que es la misma iluminación en cuanto englobante de la visión.

La inversa de un iluminar que no es visto es una visión que no es iluminada. Y me parece que de esta manera es como entiende Polo los sueños: actos de la inteligencia, a la que llegan los fantasmas, cuando está desasistida del yo cognoscente que ilumina ${ }^{40}$. El yo cognoscente y la potencia intelectual son, entonces, los extremos de la intelección esencial: desde la dependencia de la visión respecto de la persona, hasta la inserción de la potencia intelectual en el cuerpo.

En definitiva, el intelecto personal ilumina su propia esencia, y así da lugar al yo; y el yo cognoscente engloba todos los actos de intelección de orden esencial. Pero lo hace de una manera no reflexiva: porque el yo ve, pero no es visto; sino englobante de todo cuanto ve, porque ha sido previamente iluminado por la persona... cuando no se busca a sí misma. De esta manera se mantiene la diferencia entre método y tema en el acto cognoscitivo; y así Polo rechaza también la reflexividad que la filosofía medieval atribuyó a la inteligencia por inmaterial.

\section{La operación intelectual y el cuerpo propio}

El yo es el ápice de la esencia humana; como cognoscente es el iluminar que engloba todo cuanto el hombre ve, señalando la dependencia de la visión intelectual respecto de la persona; por eso es lo más alto del conocimiento en el orden esencial. En el extremo opuesto, como lo más bajo, está la operación intelectual: el límite mental. En dos palabras, y de acuerdo con la idea aristotélica de praxis teleia ${ }^{41}$, el límite mental es la conmensuración de la operación intelectual con su objeto ${ }^{42}$.

Si Aristóteles comprendió que la operación intelectual es instantánea, es decir, atemporal: que posee su fin ya, al ejercerse; por lo mismo, la operación intelectual es antecedida por su objeto, pues no se da sin él. Si no hay mediación temporal en la operación, no se pueden distinguir anterioridad y posterioridad; luego el fin es poseído ya por la operación, tanto como a ésta le antecede siempre el objeto. De modo que, para que el hombre vea, tiene que tener presente ya el objeto visto. El límite mental es, entonces, la presencia a la mente de lo conocido, que fue exhaustivamente investigada por Polo en sus primeras obras ${ }^{43}$.

[40] Cfr. Antropología trascendental, v. II; p. 77.

[41] Cfr. Metafísica IX, 7; 1048 b 18-35.

[42] Cfr. Polo, L.: Lo intelectual y lo inteligible. "Anuario filosófico" Pamplona 15-2 (1982) 123.

[43] En particular en El acceso al ser. Universidad de Navarra, Pamplona 1964; especialmente pp. 60-155.

THÉMATA. Revista de Filosofía, Nº50 julio-diciembre (2014) pp.: 247-270

doi: 10.12795/themata.2014.i50.12 


\section{a) Operación intelectual y presencia mental}

El límite mental es la operación intelectual, o la presencia mental; cuya explicación, como vamos a ver, es que la inteligencia humana, aun siendo inmaterial, está incorporada. Lo cual comporta, ante todo, su necesidad de comenzar, a partir de la información sensible; y la imposibilidad de librarse completamente de este comienzo suyo al progresar en el ejercicio de su operatividad.

La denominación de abstracción para la primera operación de la inteligencia (indicativa de su conexión con el organismo pues se abstrae de la sensibilidad) es demasiado clásica como para rectificarla. Pero sí hay que señalar que el término "abstraer" tiene la connotación de extraer, de quedarse con algo prescindiendo también de algo (por ejemplo, quedarse con la forma inteligible abandonada su materialidad sensible), que podría distraer de su preciso sentido cognoscitivo. Porque el conocimiento intelectual es un añadido personal sobre la realidad de lo conocido, una novedad que sobreviene sin quitar nada a lo real.

Por eso Polo denomina a la primera operación intelectual de otra manera: es la operación incoativa de la inteligencia, que consiste en la introducción de la presencia en el tiempo. La presencia mental permite a la inteligencia ver lo conocido, presenciarlo; e introducirla en el tiempo constituye el primer acto de visión de la inteligencia, su primera forma de ver: ya que la primera determinación de la inteligencia es la presencia del mundo en el que el hombre está $^{44}$, o en el que transcurre su vida ${ }^{45}$.

Después de la operación incoativa, la inteligencia humana se despliega en una doble dirección: pues hay dos operaciones prosecutivas. Porque lo abstracto, la noticia inicial, ni es todo lo pensable por la inteligencia (cabe después negarlo y generalizar), ni agota nuestro conocimiento de esa realidad de la que hemos tomado noticia inicial (cabe también razonar desde ésta para encontrar aquélla). A la matemática reserva Polo la unificación de ambas prosecuciones; $y$, por tanto, la matemática es una forma especial de la lógica humana, ya que el logos es la unidad de lo intelectual.

La presencia mental, por tanto, no sólo se introduce en el tiempo, sino que luego, ante todo, se extiende: pues al negar presentamos lo que aún no estaba presente. Y, por eso, la negación más que prosecutiva es consecutiva a la presencia mental: negar no es proseguir, sino conseguir ${ }^{46}$; la negación, en cuanto ajustada con la presencia mental, ha de entenderse exclusivamente como consecutiva al valor de aún no del ya ${ }^{47}$.

[44] Sobre el sentido intelectual de la expresión "estar-en-el-mundo", cfr. POLO, L.: Curso de teoría del conocimiento, v. II; lecciones $2^{\mathrm{a}}$ a $5^{\mathrm{a}}$.

[45] Cfr. Polo, L.: Quién es el hombre. Un espíritu en el tiempo. Rialp, Madrid 1991.

[46] Polo, L.: El acceso al ser, p. 92.

[47] Polo, L.: El acceso al ser, p. 126.

THÉMATA. Revista de Filosofía, Nº50 julio-diciembre (2014) pp.: 247-270 doi: 10.12795/themata.2014.i50.12 
En cambio, al razonar excluímos la presencia mental para explicitar las causas y concausalidades. Lo que ocurre es que luego volvemos a reponer la presencia... en su caso, que es éste: al objetivar y hacernos presentes esas causas; porque además de las causas explícitas, caben también el concepto, juicio y razonamiento objetivos. En virtud de éstos, es decir, por mor de la presencia mental, la razón humana es un proceder gradual, que se ejerce por fases.

La presencia, por tanto, se introduce, se extiende y se repone; así que sustenta el logos humano, toda la dinámica de la inteligencia; y de esta manera el límite mental es la salvaguarda de la esencia del hombre en tanto que distinta de la esencia fisica ${ }^{48}$.

Con todo, la operación intelectual no se conoce a sí misma, sino que se limita a presentar el objeto visto con ella, lo que con ella presencia el hombre. Desde esta perspectiva, el límite mental se ubica ya en el contexto de la carencia de identidad de la intelección humana: pues consiste en la no aparición del carácter de pensante en lo pensado ${ }^{49}$.

\section{b) Presencia mental y corporalidad}

Lo cual ocurre, decimos, porque la inteligencia humana, aun siendo inmaterial, está incorporada. E incorporada de un peculiar modo; ya que, justo porque la inteligencia humana empieza a operar introduciendo la presencia en el tiempo, no se excluye que el conocimiento intelectual del hombre acontezca de otra manera fuera del curso temporal de la historia: en las que Polo llama antehistoria o posthistoria ${ }^{50}$.

En cambio, la peculiar incorporación de la inteligencia al insertar la presencia en el tiempo es tal que no se hace cargo completamente de su propio cuerpo, no lo asume en su operación de presentar, no lo manifiesta en ella; sino que lo reduce a un mero hecho latente bajo el pensar, e incomparecido al pensar $^{51}$. La presencia mental es entonces como una moneda de dos caras, cuyo anverso es el presenciar y su reverso la latencia del propio cuerpo: que está bajo la presencia, sin comparecer en ella.

De tal modo que hay un lastre de inobjetividad al pensar: la propia corporalidad que late oculta bajo el pensar. Por este lastre, la presencia nunca es la totalidad de lo inteligible: ya que el mismo presenciar, la misma operación que se ejerce al presenciar, no es nunca presente; sino que la operación intelectual es impotente para manifestarse a sí misma. Y hago notar, entonces, que no es el cuerpo un obstáculo para el pensar, algo opuesto al espíritu; sino

[48] Polo, L.: Antropología trascendental, v. I; p. 162.

[49] Polo, L.: Curso de teoría del conocimiento, v. III; p. 388.

[50] Cfr. El hombre en la historia. Universidad de Navarra, Pamplona 2008; c. III.

[51] Sobre este hecho, cfr. Polo, L.: Curso de teoría del conocimiento, v. III; p. 407 ss.

THÉMATA. Revista de Filosofía, №50 julio-diciembre (2014) pp.: 247-270 doi: 10.12795/themata.2014.150.12 
que el límite es mental: porque es la operación intelectual, la inteligencia deficientemente incorporada, la que no puede conocerse a sí misma. Y en cambio presenta algo: lo pensado. De manera que, finalmente, pensar lo pensado no es el pensar, sino más bien su límite ${ }^{52}$.

Porque además, después, la operación intelectual confiere a lo pensado con ella ésta su limitación propia: su facticidad. La facticidad es una cuestión concomitante a la detectación del límite mental, una señal de él; aunque distinta de su abandono, como se aprecia en que se da una pluralidad de sentidos heterogéneos de la facticidad ${ }^{53}$. Y es que, en último término, el objeto presente tampoco es todo lo inteligible, sino sólo algo entendido: lo determinadamente pensado, que con frecuencia consideramos también como real de hecho. De esta manera, en definitiva, el objeto pensado es asimismo limitado: porque carece también de la omnitud inteligible.

La negación consecutiva a la primera determinación del pensamiento declara precisamente esta insuficiencia de lo pensado, y aspira entonces a la omnitud objetiva: la negación es así también generalización. Pero, como no hay una idea general máxima, la negación se continúa indefinidamente, siempre limitada por su objeto; luego la negación no permite superar la presencia mental, porque la presencia es constante en todas las operaciones intelectuales. El abandono de la presencia mental exige el conocimiento habitual.

\section{c) El conocimiento de la operación intelectual}

El límite se oculta en la operación, en tanto que ésta se ajusta con el objeto presente: el objeto se destaca y la operación se oculta. Para manifestar la operación, entonces, se necesitarán ante todo los hábitos, que son su conocimiento; y, aún después, es también posible detectar el límite mental en condiciones tales que puede ser abandonado.

Antes de los hábitos, es decir, de su manifestación, la operación intelectual puede reconocerse objetivamente en un caso: la objetivación intelectual de la circunferencia; es el acto perfecto de conciencia, superior a la conciencia imperfecta o concomitante. Porque la circunferencia es una imagen en cuya objetivación la conciencia se reconoce. Pero tan sólo se reconoce objetivamente, no en su ejercicio, aunque éste sea inseparable de ese objeto suyo; y además eso ocurre en este único caso, como corresponde a la unicidad de la presencia mental.

Tras el reconocimiento objetivo de la operación mental, el conocimiento de su ejercicio, su iluminación, puede hacerse de tres maneras, aun antes de detectarla como un límite susceptible de ser abandonado.

[52] Polo, L.: El ser I: la existencia extramental. Universidad de Navarra, Pamplona 1966; p. 89.

[53] Cfr. Polo, L.: Curso de teoría del conocimiento, v. III; p. 395.

THÉMATA. Revista de Filosofía, Nº50 julio-diciembre (2014) pp.: 247-270 doi: 10.12795/themata.2014.i50.12 
La inicial se reduce a una mera variación del acto intelectual ejercido por la potencia: en lugar de atender a lo presente, considerar su presencia. De acuerdo con esta variación, se aprecia que lo presente no es todo lo posible, lo presenciable, lo pensable; y de esta manera se inicia y se ejerce la operación negativa de la inteligencia, la generalización, que es consecutiva a la presencia mental: su seguir ejerciéndose.

Después, la iluminación de la operación puede mantenerse hasta manifestarla en cuanto distinta de su objeto, es decir, separándola de él. Esta iluminación es propiamente el hábito adquirido; y permite la prosecución racional de la operatividad intelectual, la que explicita las causas en pugna con la presencia mental manifiesta.

Y, finalmente, la operación ejercida puede ser iluminada también a una con su objeto, suscitando en tal caso las ideas simbólicas: los simbolos sobre los que versa la claridad experiencial son, entonces, manifestaciones de la presencia mental ${ }^{54}$. Cuando el yo es cognoscente de sus propias operaciones intelectuales, las idea y torna así simbólicas. Y, entonces, remiten más allá de ellas: desde su índole intencional hacia la realidad; si bien, como simbólicas que son, no llegan a descifrar cabalmente esa remisión. El descifrar las ideas simbólicas no es asunto del yo cognoscente, sino que compete al abandono del límite, es decir, al intelecto personal.

Las ideas simbólicas que registra Polo, en correspondencia con las operaciones intelectuales iluminadas, son éstas: el yo (suscitado al idear la conciencia), Dios (al idear la generalización o negación), la distinción real de esencia y existencia (con tres símbolos suscitados al idear la abstracción, concepción y afirmación: las ideas de naturaleza, sustancia y esencia) y los axiomas lógicos (símbolos procedentes de idear la fundamentación racional). No hay, en cambio, un símbolo de la persona; porque ésta, como es transparente, reenvía de suyo, sin necesidad de ningún símbolo.

En suma, la manifestación de la presencia mental es gradual: el primer grado la manifiesta como un ver detenido (es el hábito adquirido), el segundo como verbo (más que un ver, un veré futurizado: así son los símbolos que suscita el yo cognoscente) y el tercero detectándola en condiciones tales que cabe abandonarla ${ }^{55}$.

Estas condiciones son la dependencia que guarda el límite mental respecto de la libertad personal: pues la persona puede desprenderse de la presencia a la mente, en tanto que posee un futuro propio y no desfuturizable ${ }^{56}$. Y de eso corresponde tratar ahora: del abandono del límite mental.

[54] Polo, L.: Antropología trascendental, v. II; p. 217.

[55] Polo, L.: Antropología trascendental, v. II; p. 89.

[56] Cfr. Polo, L.: Antropología trascendental, v. I: la libertad y el futuro; pp. 230 ss.

THÉMATA. Revista de Filosofía, №50 julio-diciembre (2014) pp.: 247-270 doi: 10.12795/themata.2014.i50.12 


\section{d) Más allá de la operación intelectual}

Si el límite es la operación intelectual, es decir, el ajuste entre la operación y su objeto, podrá abandonarse bien por el lado del objeto, hacia la realidad extramental, con la primera y segunda de sus dimensiones; o bien por el lado de la operación, hacia la realidad personal: son la tercera y cuarta dimensiones del abandono.

A su vez, cabe añadir que el abandono del límite mental puede ser completo, esto es, prescindiendo enteramente del límite, o sea, de las operaciones mentales. Lo cual se consigue inicialmente con la primera dimensión del abandono; pero, inmediatamente después, con la tercera: sin la que no se abandona el límite completamente. O bien el límite mental puede abandonarse también contando con el mismo límite, como para distanciarse de él: bien hacia lo que es inferior al límite, mediante cierta pugna entre ambos que torna explícita la causalidad extramental (la segunda dimensión del abandono); o bien hacia lo que es superior al límite: que es el yo cognoscente, el cual explica y engloba el límite mental (la cuarta dimensión de su abandono).

También se puede decir que, si el límite mental es la operación intelectual, su abandono se corresponderá con el conocimiento habitual. Tanto los hábitos adquiridos por la inteligencia mediante el ejercicio de sus operaciones, al conocerlas (segunda dimensión); como los hábitos personales, que brotan de la persona (las otras tres dimensiones). De modo que la operación intelectual, el límite mental, se corresponde propiamente con la inteligencia; mientras que su abandono, en cambio, con el intelecto personal. Es decir: con el alcanzar que luego busca (la tercera dimensión), con el iluminar que permite ver (la cuarta dimensión) y con el que encuentra (las dos primeras dimensiones; aunque para la segunda, como la esencia extramental está coordinada con la inteligencia humana, su encuentro exige la manifestación de la operatividad de ésta: los hábitos adquiridos por la razón).

En definitiva: el límite corresponde al operar de la inteligencia, mientras que su pluridimensional abandono es la diversa actividad del intelecto personal, el ejercicio de su dimensión metódica. Porque la búsqueda de réplica, en cambio, no es una dimensión del método propuesto ${ }^{57}$, pues el abandono del límite mental no da más de sís8: en ella rige sólo la dimensión temática del intelecto personal, privada de su valor metódico. Se produce, por tanto, un trueque: en vez de su valor metódico, la ordenación del intelecto al tema que lo trasciende: es la fidelidad del intelecto personal a su indole de intelecto creado ${ }^{59}$.

[57] POLO, L.: Antropología trascendental, v. I; p. 212.

[58] Ibídem, v. I; p. 11.

[59] Ibidem, v. I; p. 212.

THÉMATA. Revista de Filosofía, Nº50 julio-diciembre (2014) pp.: 247-270 doi: 10.12795/themata.2014.i50.12 


\section{Conclusión: la dualidad de coincidencia y separación en la intelección humana}

Recapitulemos. La indagación poliana sobre la carencia de unidad de la intelección humana, que establece -en cambio- su dualidad, nos condujo a rechazar, en un primer lugar, la identidad del intelecto personal: sentando la distinción entre su existencia y su esencia; es decir, entre su transparencia, que se ubica en el ámbito de la intimidad personal, y su iluminar hacia fuera.

En segundo lugar, nos condujo a la distinción entre la actividad cognoscente del yo y la potencia intelectual, que es la que media entre la iluminación que permite ver y la visión: pues el yo cognoscente permite a la inteligencia ver al iluminar, pero él mismo nunca es visto, sino el iluminar englobante. Este englobar abraza toda la interioridad del yo humano; que, sin embargo, es la manifestación hacia fuera de la persona.

De modo que la expresión el yo pensado no piensa incluye esos dos significados; duplicidad que el mismo Polo ha reconocido: pues, en sus primeras obras -confiesa- no distinguía con nitidez persona y yo, y acuñé la fórmula "núcleo del saber'60. Esos dos significados son éstos: ante todo, que la persona no se replica a sí misma, esto es lo capital; y luego, que el yo no se ve a sí mismo. Por eso, Polo termina por decir que esta observación (el yo pensado no piensa), más que a la tercera, interesa decisivamente a la cuarta dimensión del abandono del límite mental ${ }^{61}$.

A todo lo cual hemos añadido, en un tercer lugar y finalmente, que la operación intelectual tampoco se conoce a sí misma; es decir, que tampoco hay identidad entre la operación intelectual y su objeto, esto es, entre la presencia mental y lo presente, diferencia que es el mismo tema del límite mental; con él se abre el hombre hacia el exterior, es decir, hacia la exterioridad de lo inferior a sí mismo.

Si la intelección humana carece de unidad en todos sus niveles, será porque lo suyo es más bien la dualidad: la que distingue el método y el tema del acto cognoscitivo. Y Polo establece esta dualidad enlazando coincidencia y separación. En los actos cognoscitivos del hombre, desde el intelecto personal a la operación mental, se distinguen sus dimensiones temática y metódica; a la primera conviene la coincidencia, a la segunda la separación. Y de tal manera que hay una correspondencia inversa entre ambas: a más coincidencia, menos separación; y viceversa.

Y así, la operación intelectual, que es el límite mental, constituye una coincidencia máxima, de acuerdo con la cual se establece la verdad en su inicial

[60] Antropología trascendental, v. II; p. 69, nt. 86. Lo hice notar en la nota explicativa de la publicación de su escrito La persona humana como ser cognoscente. "Studia poliana" 8 (2006) 53.

[61] Antropología trascendental, v.II; p. 18, nt. 25.

THÉMATA. Revista de Filosofía, №50 julio-diciembre (2014) pp.: 247-270

doi: 10.12795/themata.2014.i50.12 
sentido fenomenológico; de acuerdo con ella se admite el aforismo parmenídeo lo mismo es pensar y ser: son lo mismo... cuando al pensar se obtiene la verdad. Pero, simultáneamente, hay en la operación intelectual una separación mínima: pues la operación se conmensura con su objeto; de modo que, operativamente, intellectus in actu est intellectum in actu ${ }^{62}$.

En cambio, el intelecto personal coincide mínimamente con el tema que busca, puesto que éste le trasciende enteramente; y por eso hay una separación máxima entre el intelecto personal y su tema, que es el verbo divino; ya que, como suele decir Polo, la persona humana es más distinta de Dios que de la nada ${ }^{63}$.

Con todo, si la divergencia entre la operación intelectual y el intelecto personal es ya extrema, más imposible será aún la comparación entre la mismidad de pensar y ser propia del límite mental y la identidad divina del ser y el entender, términos ambos que son por completo incomparables; pues la identidad originaria es irreductible al límite mental, al que más bien anula ${ }^{64}$.

Si ante la sabiduría divina desaparece el saber humano, es inane la pretensión hegeliana de un saber absoluto. Pero la filosofía poliana del límite mental no decae por ello en actitudes pesimistas: escépticas, empiristas o voluntaristas; ni siquiera en el socrático sólo se que no se nada, o en la cusana docta ignorantia. Porque el saber humano es limitado, entre otras cosas porque es un inteligir creado, y además incorporado de tal modo que no dispone plenamente de su propio organismo. Pero, justamente porque ha sido creado y porque dispone hasta cierto punto de su organismo, justamente por ello, es un saber y un inteligir, no un conjeturar, fingir saber o ignorar.

Por eso, si atendemos, en lugar de a los extremos, a todos los actos cognoscitivos intermedios entre la operación intelectual y el intelecto personal, cabe hablar de una progresiva separación de la actividad cognoscitiva respecto de los temas conocidos con ella. En atención a esto, el propio Polo ha señalado ${ }^{65}$ la vinculación de su propuesta metódica con la noción de separación. Ésa que Aristóteles asignó al intelecto agente ${ }^{66}$; y el aquinate a la temática metafísica, es decir, a las sustancias inmateriales ${ }^{67}$ : de aquí su distinción entre abstractio y separatio para establecer el método de la metafísica ${ }^{68}$.

La progresiva separación, respecto de la operación intelectual, en que consiste el abandono del límite mental apela a la libertad trascendental de la persona: pues por ella, el hombre puede irse desprendiendo del presente para orientarse hacia el futuro.

[62] Tomás de Aquino: Summa theologiae I, 85, 2 ad 1.

[63] Antropología trascendental, v. II; p. 211.

[64] Cfr. Polo, L.: El ser I: la existencia extramental, pp. 333 ss.

[65] Cfr. Antropología trascendental, v. II; p. 19, nt. 27.

[66] Cfr. De anima III, 5; 430 a 22-3.

[67] Cfr. Expositio super librum Boethii De Trinitate, q. 5, a. 4.

[68] Cfr. Gelonch, S. R.: "Separatio” y objeto de la metafísica. Eunsa, Pamplona 2002.

THÉMATA. Revista de Filosofía, Nº50 julio-diciembre (2014) pp.: 247-270 doi: 10.12795/themata.2014.i50.12 